\title{
Trabalhonecessário

DOI: https://doi.org/10.22409/tn.v18i35.40514

\section{ENTREVISTA DE JOSÉ LUIZ DEL ROIO - GUARDIÃO DA MEMÓRIA OPERÁRIA NO PERÍODO DA DITADURA MILITAR (1964-1985) ${ }^{1}$}

\author{
Elina Pessanha²
}

A entrevista que se segue registra uma das mais importantes iniciativas para a preservação da memória dos trabalhadores brasileiros. Ao abrigar, no período pós-1964, um rico acervo contendo material de trabalhadores e sobre trabalhadores, salvando-o da destruição e coordenando sua atribulada transferência para a Itália, onde foi acolhido pela Fundação Feltrinelli, de Milão, o historiador José Luiz del Roio deu uma contribuição inestimável à história de nossa classe trabalhadora e de suas iniciativas de organização e resistência desde o início do século XX.

Hoje, quando essa documentação original já se encontra no Brasil, vale recordar o longo trajeto que cumpriu. E também reafirmar o valor fundamental desse conjunto de fontes, para a recuperação e compreensão mais fina do duro caminho trilhado, pelos trabalhadores, na tentativa de construir uma sociedade mais justa, igualitária e democrática.

Como estudiosa das relações de trabalho, da resistência dos trabalhadores e de suas lutas por direitos, e também como coordenadora do Arquivo de Memória Operária do Rio de Janeiro, da UFRJ - depositário há décadas de cerca de 100 mil fotogramas em microfilmes gerados por del Royo e adquiridos pela universidade - só posso parabenizar esta revista pela recuperação da trajetória do relevante acervo e pela justa homenagem que se presta ao seu principal protetor e gestor.

\footnotetext{
${ }^{1}$ Recebido em 20/11/2019. Aprovado pelos editores em 27/12/2019. Publicado em 23/01/2020. 2 Doutora em Ciências Sociais (USP), professora do IFCS/UFRJ, no Rio de Janeiro/RJ, Brasil. É pesquisadora do CNPq e coordenadora do AMORJ. E-mail: elina.pessanha@terra.com.br. ORCID: http://orcid.org/0000-0001-8443-1534.
} 


\section{José Luiz Del Roio}

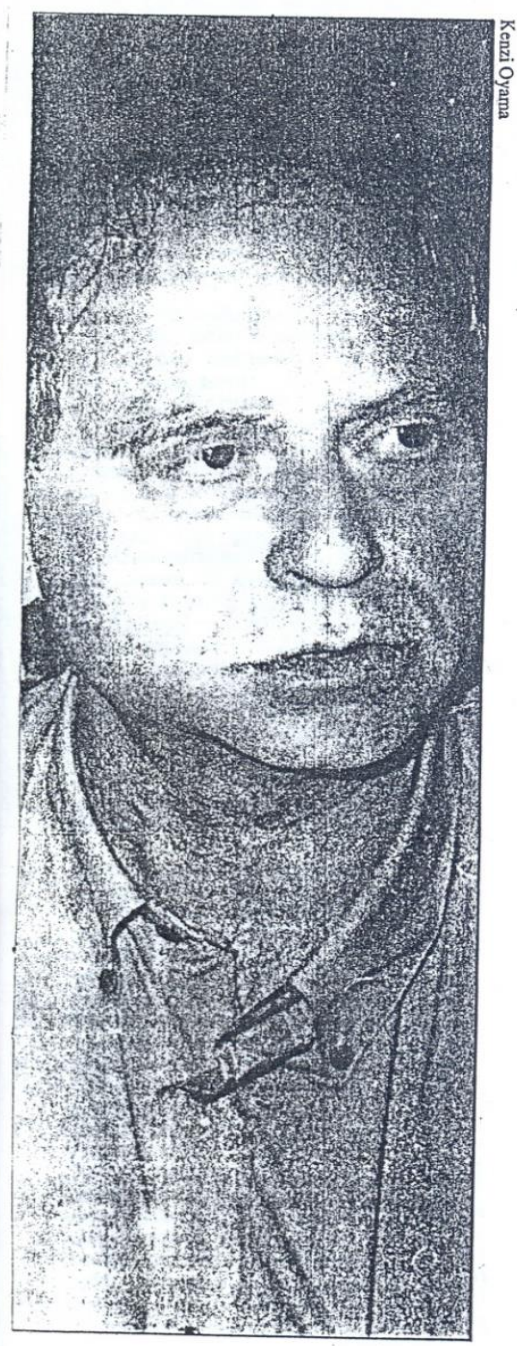

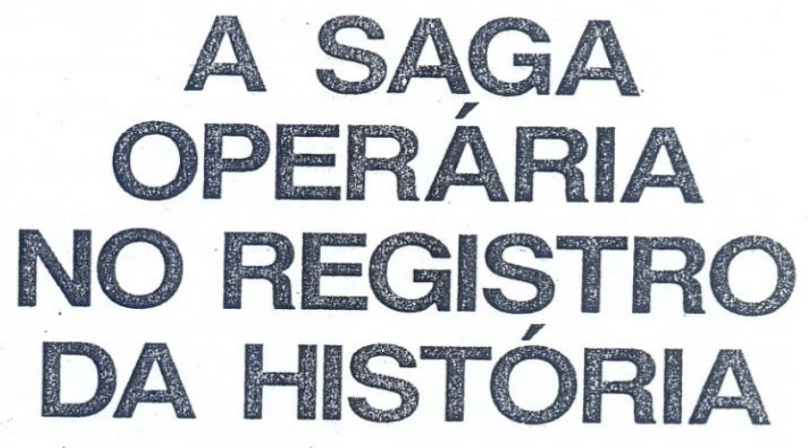

O presidente do Arquivo de Milão fala sobre o maior e mais importante acervo documental do movimento operário brasileiro no exterior

Meúoria

esquisador na Fundação Feltrinelli e presidente do Arquivo Histórico do Movimento Operário Brasileiro (ASMOB), em Milắ, Jose Luiz Del Roio nasceu em 1942 em São Paulo, no bairro do Bixiga. De famnia italiana, viveu no interior do Estado, em Bragança Paulista. Cursou a Faculdade de masoria, Letras e Ciencias HumaExilad rou em Cuba se na Itrlia logo depois do golpe contra o governo socialista de vador Allende, em 1973

Del Roio esteve no Brasil no final de 1991 e visitou mento de Patrimbito HistopartaEletropaulo, no andar r do prédio Alexandre Mackenzie, onde conversou com José Antonio Segatto, Ricardo Maranhão Dias antes do Natal, em meio ao barulho de trânsito e corre-corre dos festejos natalinos vindos da Xavier de Toledo, centro paulistano ("parece Milăo"), o autor de Enrico Berlinguer e a evolucāo do $P C I$ e 1 de maio: cem anos de luta (1886-1986) falou à Memória. sobre seu trabalho no maior e mais importante acervo do movimento operario e socialista fora do Brasil. Foi ali, por exemplo, que o escritor Fernando Morais conseguiu preciosas informaçōes para compor o livro Olga, além de ter sido local de peregrinação para a pesquisa de inumeros historiadores e cientistas sociais brasileiros e estrangeiros.

Ipto. Patrinorio Histórico da Eletrohaulo Jullo/set. 1992 


\section{Entrevista}

A SAGA OPERÁRIA NO REGISTRO DA HISTÓRIA: JOSÉ LUIZ DEL ROIO $O$ presidente do Arquivo de Milão fala sobre o maior e mais importante acervo documental do movimento operário brasileiro no exterior ${ }^{3}$

Pesquisador na Fundação Feltrinelli e presidente do Arquivo Histórico do Movimento Operário Brasileiro (ASMOB), em Milão, José Luiz Del Roio nasceu em 1942 em São Paulo, no bairro do Bixiga. De família italiana, viveu no interior do Estado, em Bragança Paulista. Cursou a Faculdade de Filosofia, Letras e Ciências Humanas da USP, na rua Maria Antônia. Exilado em 1969, após o AI-5 [Ato Institucional n. 5], morou em Cuba, Peru, Chile, fixando-se na Itália, logo depois do golpe contra o governo socialista de Salvador Allende, em 1973.

Del Roio esteve no Brasil no final de 1991 e visitou o Departamento de Patrimônio Histórico da Eletropaulo, no andar rés-do-chão do prédio Alexandre Mackenzie, onde conversou com José Antonio Segatto, Ricardo Maranhão e eu. Dias antes do Natal, em meio ao barulho de trânsito e correcorre dos festejos natalinos vindos da Xavier de Toledo, centro paulistano ("parece Milão"), o autor de Enrico Berlinguer e a evolução do PCI e $1^{\circ}$ de maio: cem anos de luta (1886-1986) falou à Memória sobre seu trabalho no maior e mais importante acervo do movimento operário e socialista fora do Brasil. Foi ali, por exemplo, que o escritor Fernando Morais conseguiu preciosas informações para compor o livro Olga, além de ter sido local de peregrinação para a pesquisa de inúmero historiadores e cientistas sociais brasileiros e estrangeiros. (Roniwalter Jatobá)

\section{Na montagem do Arquivo Histórico do Movimento Operário (ASMOB), em Milão, tivemos preciosas colaborações. Eurico Berlinguer, ex-secretário geral do PCI, deu uma ajuda muito importante para levar o arquivo de Astrojildo Pereira para a Itália}

Memória - Presidente do Arquivo Histórico do Movimento Operário Brasileiro (ASMOB) em Milão, como é que você foi parar na Itália e basicamente na área da memória operária?

José Luiz Del Roio - Acaso absoluto. Eu tinha nada a ver com isso, não. Fui parar na Itália por motivos de exílio político. Depois de viver um pouco em vários países, acabei me fixando na Itália, embora fosse um país extremamente difícil. A Itália nunca deu asilo político para ninguém, a não ser para países do Leste. E isso sempre gerou muita dificuldade para

${ }^{3}$ Transcrição da entrevista publicada por Memória. Departamento Patrimônio Histórico da ELETROPAULO, São Paulo, p. 2-6, julho / set. 1992. 
exilados. Milão mesmo era uma cidade praticamente deserta de brasileiros naquele período, pelo menos de brasileiros da área política. O que aconteceu é muito simples: eu era muito amigo do líder operário Roberto Morena, que morava em Praga, e sempre que podia ele vinha a Milão. Roberto Morena foi um líder operário estranhíssimo. Por exemplo, adorava ópera. Então quando podia pegava o trem e vinha ver algum espetáculo em Milão. Conheci o Morena ali. Personagem deliciosa, maravilhosa, ele me disse que tinha muito material, parte estava no Brasil e parte estava em Praga. E ele gostaria que esse material ficasse junto, com a possibilidade de ser consultado. Bem, a situação política dele em Praga não era boa, ele tinha apoiado a Primavera de Praga em 1968. Aí, ele propôs que eu arrumasse um lugar para trazer seu material. Em 1977, Morena morre em Praga, e aí nós ficamos com medo de perder seus arquivos. Até dona Eugênia, mulher de Morena, insistiu muito que ele teria dito que o material deveria ser passado ao Maurício Martins de Melo e a mim. Então tivemos que achar um local para colocar esse arquivo. Na época, o Maurício trabalhava na Feltrinelli como arquivista e, assim, resolvemos discutir a questão com a sua direção, que topou na hora colaborar e ajudar na estruturação.

Memória - Então ele é constituído de documentos do Brasil e dos que estavam em Praga?

José Luiz - Sim, era todo o material de Roberto Morena.

Memória - E o acervo de um dos fundadores do PCB, o do Astrojildo Pereira? Como foi parar em Milão?

José Luiz - Nós começamos a recolher a recolher outros materiais, como, por exemplo, o do antropólogo Túlio Cepeli, da Universidade de Perugia, cujo pai, amigo de Prestes, tinha sido exilado em São Paulo. Quando voltou para a Itália não tinha levado seu arquivo. Então, me interessou muito recolher documentos do exílio. Quase no final de 1978, já se abriam novas possibilidades. Vocês aqui no Brasil estavam batalhando pela anistia, e no fim esta anistia acaba saindo, e os exilados brasileiros tinham publicado muito, tinham feito muitas revistinhas, muito jornal, todas as correntes, tendências, grupos. Na primeira fase, começamos a recolher tudo isso. Então, a segunda fase foi reunir material do exílio, o que se publicava na Suécia, na Dinamarca, na Argélia, na América Latina. Nesse bolo todo, surgiu a possibilidade de levar o arquivo do Astrojildo, que estava em situação absolutamente dramática no Brasil. Então batalhamos para que esse material fosse para o exterior. Assim, a documentação do Astrojildo chega também em 1978. A operação não foi fácil, ao contrário, foi bastante complicada. Era uma tonelada e meia de papel.

Memória - Houve doações, além do Astrojildo, de peso?

José Luiz - Substancialmente, a parte central mais importante sempre foi do Astrojildo mesmo, embora tivesse coisas muito interessantes do Morena, mas referentes à questão sindical. Depois, tivemos outras contribuições, 
sempre aos pedacinhos, coisas às vezes que as pessoas guardavam com carinho. Vamos pensar: Paulo Cavalcanti, quando ele achava que tinha alguma coisa muito interessante sobre o PCB em Pernambuco; Jorge Amado, de vez em quando. O próprio Jorge mandou um material sobre José Medina, que foi secretário do PCB em 1943. O Jorge mandou coisas dele também. Oscar Niemayer mandou alguma coisa. E depois sempre acontecia que alguém mandava, como um arquivista gaúcho chamado Marçal que tem um arquivo próprio sobre a história operária no Rio Grande do Sul.

Memória - Como foi a operação de transferência do arquivo do Astrojildo? José Luiz - O arquivo dele sofreu com a repressão e parte se perdeu. Quando o Astrojildo morre, em 1965, o arquivo ficou com o seu grande amigo historiador, general Nelson Werneck Sodré. Evidentemente, ele teve dificuldades depois com a repressão que foi apertando. Aí, o arquivo começa a ir para os porões das diversas casas de amigos, começa a viajar pelo interior. Além disso, o clima brasileiro é ruim para a guarda de coisas em porões: emboloram. Depois ele sofreu desmembramento. Em 1975, uma parte do arquivo estava dentro das gráficas da Voz Operária. Esta parte se perdeu; não voltou até hoje. Deve estar na polícia. Parte dos livros do Astrojildo foi deixada na Unicamp e nas portas de bibliotecas; esse material sumiu dentro das bibliotecas. Foi classificado sem se saber que a origem era do Astrojildo. Outra parte do material, por exemplo, foi simplesmente entregue para sebos; por sorte, uma parte disso foi recuperada pelo professor Edgard Carone e pelo empresário José Mindlin. Então é um arquivo que sofreu tudo que tinha direito. Aconteceu com ele o mesmo que com muitas pessoas nesse país durante a ditadura. As pessoas perdiam o emprego, ficavam clandestinas, de vez em quando iam para a cadeia, levavam um pau; com ele aconteceu a mesma coisa. Então, nesse momento, todo mundo falava nesse arquivo, todo mundo queria ver esse arquivo. Apesar da repressão tinha gente muito interessada em estudar o movimento operário, todo mundo falava deste misterioso e fundamental arquivo. Isso tudo passou por uma discussão e eu perguntei ao Luiz Carlos Prestes se ele sabia onde estava, como estava e se era possível retirá-lo do Brasil. Ele pessoalmente apoiou a ideia, e nos incentivou muito, nos deu muito apoio. E a partir disso nós conversamos com a direção do Partido Comunista Brasileiro que estava exilada. E através dela nos deram alguns contatos e particularmente foi uma companheira (não vou citar o nome pois não tenho autorização), passando pela figura de José Sales e Marli Viana, que nós tivemos o contato de onde estava e o que restava do arquivo; e esta companheira sozinha enfrentou o leão para tirar uma tonelada de documentos do PCB do país em 1977 e 1978. "Todo mundo que trabalha com a história social brasileira passou pelo Arquivo de Milão. Tínhamos séries de documentos que hoje é carne de vaca mas até aquele momento não era."

Memória - A retirada foi conseguida de maneira tranquila? 
José Luiz - Foi tranquila porque foi levada como se fosse uma mudança, como alguém que se mudasse. Chegaram lá coisas ridículas, como roupa de cama, um monte de coisas juntas, porque era uma mudança. Eram vários baús. De qualquer forma houve um incentivo na alfândega para que não nos investigassem demais. A ditadura também criou, apesar da sua figura moralista, um mar de corrupção. Neste caso específico a possibilidade de corrupção foi benéfica. Foi terrível depois, porque o navio demorou cinco meses para chegar. O navio não saiu do Brasil e foi direto para a Itália, resolveu dar antes uma volta pela Ásia. Foram meses de inferno, mas acabou chegando. É necessário aqui lembrar que Enrico Berlinguer - ex-secretário geral do PCI - deu uma ajuda, inclusive pessoal, muito importante para se levar o arquivo do Astrojildo para a Itália.

Memória - Mas é comum o pesquisador brasileiro ir à Itália fazer algum tipo de trabalho?

José Luiz - Em 1978, o arquivo chegou aos pedaços. Foi muito difícil a catalogação. Muitos jornais estavam irrecuperáveis. O mofo tinha comido tudo, sobretudo cartas e a parte fotográfica. Foi feito um trabalho de recuperação de fotos. Foi um arquivo de difícil classificação, até porque Astrojildo guardava tudo. E era muito anárquico na sua organização. Por exemplo, todas as suas anotações políticas ou literárias ele adorava fazer em cédulas eleitorais da época. Então, você recebe um bolo de dez mil cédulas bagunçadas, como é que você põe em ordem aquelas malditas cédulas? Temos poucas cartas do Astrojildo. A correspondência é só a que ele recebe, não a que envia. Com o Morena é diferente: cada carta que envia ele toma nota, copia a sua carta e depois anexa a resposta. É uma maravilha. Um arquivista vê aquilo e chora de alegria. Mas Astrojildo não, é uma grande confusão. Assim, a partir de 1979 tivemos uma quantidade muito grande de pessoas que foram lá. Quase todo mundo que escreveu sobre a história operária do Brasil, todos necessariamente pesquisaram lá. Muitos norteamericanos. Vieram também franceses, soviéticos, alemães, ingleses. Todo mundo de um jeito ou de outro que trabalha com história social brasileira, e um pouco a latino-americana, foi lá, mesmo porque tínhamos a única coleção do mundo da Correspondência Sul-Americana, revista do Bureau SulAmericano da Internacional Comunista. O Trabalhador Latino-Americano, que é a revista da Internacional Sindical Vermelha da América Latina, ou seja, tínhamos uma série de documentos que hoje é carne de vaca mas até aquele momento não era.

Memória - Quais são os marcos cronológicos?

José Luiz - Os marcos cronológicos são do fim do século passado até a década de 80. Mas começa-se politicamente a partir de 1910. É claro que temos jornais latino-americanos mais antigos, que estavam nos pertences do Astrojildo. Creio que o mais antigo deve ser o jornal anárquico-comunista 
da Argentina de 1896. Temos alguma documentação de 1858, mas é pouca coisa.

Memória - O Arquivo do Estado da Secretaria de Estado da Cultura financiou, na gestão Fernando Morais, a microfilmagem de alguns documentos. Quais os documentos que escolheram e como é que o pesquisador, aqui em São Paulo, pode usar o material?

José Luiz - A partir de 1979 a nossa preocupação foi divulgar o nosso acervo ao máximo, porque existia uma tendência no Brasil de quem descobre um documento sentar em cima dele até fazer a tese, ou até fazer não sei o quê. Mas não foi fácil, financeiramente difícil. Então, decidimos que, no primeiro financiamento, começaríamos a microfilmar, que era uma forma de socializar. Assim, fizemos um primeiro bloco de microfilmes em 1982 e um segundo em 1983. Estes nós passamos, não completo, mas em boa parte, à Universidade de Campinas. Uma parte consistente foi para a biblioteca Mário de Andrade, um presente da presidente da Província de Milão à administração Mário Covas. Esses microfilmes estão à disposição na biblioteca Mário de Andrade e sei que foram muito consultados, mas infelizmente nem todos sabem disso. O material foi inclusive para outras regiões, mesmo Campina Grande, Paraíba, recebeu alguma coisa. Vários pontos do país receberam, mas nunca completo. Já a Secretaria da Cultura, na figura do secretário Fernando Morais, que particularmente tinha estado no arquivo em Milão para consultar sobre Olga, fez a proposta de que colaboraria, dentro do possível, com a microfilmagem. E nós fizemos então uma segunda grande microfilmagem, sobretudo do material do período da luta armada no Brasil. Todos esses materiais estão à disposição no Arquivo do Estado.

\section{Após 1945, iniciou-se na Itália um trabalho para a riquíssima história política do socialismo italiano e também europeu}

Memória - A Fundação Roberto Marinho está fazendo um acordo de cooperação técnica para pesquisa e preservação da memória do PCB. Como é a relação das empresas privadas com a história da esquerda, na Itália? José Luiz - Na prática não existia. Na Itália depois da Segunda Guerra Mundial - depois de vinte e dois anos de fascismo e três de guerra no seu território - começa um movimento de esquerda muito forte, tanto sindical (CGL), como do Partido Socialista e Partido Comunista. São milhares de militantes que, por exemplo, não conheciam um senhor chamado Antonio Gramsci. E por que deviam conhecer? Ele tinha morrido há mais de 10 anos. Iniciou-se então um trabalho para recuperar a riquíssima história política do socialismo italiano, não só italiano, mas europeu. De um lado, o Instituto Gramsci, que foi criado pelo Partido Comunista, então financiado pelas suas estruturas; criaram-se diversos Centros do Partido Socialista, também financiados ou pela direção central ou em parte financiado também pelo Estado, mas pelo Estado através dos partidos fortes. Por outro lado, a 
Fundação Feltrinelli, cujo fundador não era ligado diretamente ao partido, embora na prática fosse, Era Giangiacomo de Feltrinelli um dos homens mais ricos da Itália. Com longa tradição da família burguesa, riquíssima, ele foi assistente contra o fascismo. E assim foi feito. Ele agrupou o que tinha de melhor de historiadores da Itália, historiadores contemporâneos do fascismo, do socialismo, e mesmo da Europa. Feltrinelli virou a Europa e parte do mundo comprando tudo. Comprou até coisas absurdas, como a bandeira da Comuna de Paris.

Memória - E os manuscritos?

José Luiz - Sim, os originais. Há manuscritos da Feltrinelli que eram até menos importantes como estudo para a Itália, mas são interessantíssimos: os de Lenin e os originais de Grundrisse, de Marx. Ele comprou tudo. O material mais importante, de qualquer forma, não são os escritos econômicos de Marx e Engels, mas é o jornal de Graco Babeuf de 1790, cópia única no mundo do homem que criou o movimento comunista como ideia, como palavra. Tem todo o material do imaginário do pré-socialismo, todas as primeiras edições dos fisiocratas, tem esboço inclusive do arquivo privado da biblioteca François Fourier. Todo esse tipo de material acabou batendo lá.

\section{Memória - E o ASMOB?}

José Luiz - Não é um arquivo substancialmente de partidos ou do Partido Comunista ou do movimento na época da resistência à ditadura militar. É mais amplo. Aqui do Brasil tem a trajetória do anarquismo, porque, afinal de contas, toda a fase de 1910 a 1922, 23 e 24 o Astrojildo guardou o que ele achava. Claro, primeiro ele era anarquista; depois, até quando não era, ele guardava para continuar brigando com os amigos. Tem ainda uma parte da formação do Movimento Unitário dos Trabalhadores em 1945, até a criação da CGTB clandestina, vamos dizer, que vai até 1953, 54. Tem dez anos de documentos sindicais muito interessantes. $\mathrm{E}$ isto não é partidário, era $\mathrm{o}$ material do Morena, porque ele tinha sido secretário da CGTB. Todas as cartas de Roberto Morena deste período estão no Arquivo do Estado.

Memória - E a relação com as empresas privadas?

José Luiz - A Itália é vista por muitos como um dos paraísos sobre a Terra. A Itália que se considera a quinta potência mundial, a Itália da Olivetti, grande produtora de computadores, da Fiat... mas quando chega na questão arquivística faz chorar. Não tendo o Estado assumido a importância que é isso para a Itália, o dinheiro falta de forma incrível. Os arquivos e as bibliotecas estão numa situação desesperadora. As bibliotecas estão em prédios muito antigos, prédios de 300, 400, 500, 600 anos. Hoje, não são compatíveis mais com a massa de material que entra. Realmente falta uma política. As bibliotecas são muito atrasadas, não informatizadas, e há também a resistência de parte dos sindicatos para entenderem o que tem que ser feito dentro desta nova fase de mudança e modernização. Isso tem 
golpeado muitíssimo a arquivística italiana. Nesse sentido, as fundações que tratam a história do movimento operário da Itália vivem um momento dramático. Quanto às empresas privadas, existem colaborações, mas as que eu conheço, no entanto, são diretamente do movimento operário. Além disso, a crise séria que golpeia a esquerda mundial, golpeia também os bolsos dos sindicatos na Itália. Então, neste momento, a situação dos estudos sociais, dos movimentos sociais, estudos operários na Itália, é dramática. O Instituto Gramsci, o movimento operário socialista e a Feltrinelli vivem uma situação parecida com muitas instituições brasileiras que eu conheço do mesmo ramo. O dinheiro não basta para pagar os seus funcionários, que já foram em quase todas as instituições reduzidos a $60 \%, 70 \%$. E sem informatização, sem nada, a situação é muito difícil.

Memória - Os jornalistas no Brasil têm enriquecido a historiografia brasileira. Alguns exemplos: Fernando Morais com Olga e mais recentemente o José Ramos Tinhorão com o livro A música popular no romance brasileiro. Esta prática do jornalista entrar na seara da pesquisa historiográfica é fenômeno só brasileiro?

José Luiz - Não, não acredito, embora o jornalista... você citou dois exemplos nobres. Mas existem menos nobres que passam pela fofoca, como, por exemplo, descobrir quanto ouro de Moscou chegou ou não chegou em 1935 ou 1964. Isto não é historiografia, é luta política de baixíssimo nível. Agora posso citar trabalhos jornalísticos, como a última biografia de Gramsci feita pelo Fiori, como jornalista e não como historiador, exatamente um monumento dando uma contribuição historiográfica imensa. Eu acho que, se bem feito, é uma feliz simbiose.

\section{Recordo dos primeiros anos em São Paulo, de cabras que passavam pela Bela Cintra e um homem vendendo leite}

Memória - Você nasceu em São Paulo e aos 6 anos foi para Bragança Paulista e depois retornou a São Paulo. Conte um pouco dessa trajetória.

José Luiz - Ainda me recordo dos primeiros anos em São Paulo. Morava na rua Bela Cintra. Recordo de cabras que passavam pela Bela Cintra e um homem vendendo leite. Ele tirava o leite das cabras. Outra coisa que me marcou muito, tinha 12 anos, foi o famoso IV Centenário. Vim para São Paulo: 25 de janeiro de 1954. Marcou muito. São Paulo tinha chegado a 2 milhões de habitantes e aí a cidade não parou de crescer. Depois vim para São Paulo para tentar estudar e trabalhar. A São Paulo nos anos 60 era muito difícil. E também nesse momento eu já tinha me ligado à militância. Depois do golpe a vida política ficou difícil: o problema da repressão, o desespero que o golpe causava. A nossa impressão, pelo menos para nós militantes de esquerda, era que nosso futuro tinha acabado. Isso era um desespero, tanto espaço, tanta luta, e tanta ilusão. O que íamos fazer? A possibilidade que se abria era nada: estudar direitinho e ser empregado em algum lugar. Isso era insuportável. São Paulo passou a ser, como era para tantos milhões de jovens, 
um terreno de batalha. Ocupado por tropas estranhas, alheias. Isso tudo acabou criando uma grande decepção. Da militância do PCB - eu era dirigente do PCB aqui no Estado -, eu me liguei muito a Carlos Marighela e a Câmara Ferreira. Evidentemente com tudo aquilo que comportava tal escolha política. Até que, em 1969, a organização, ALN, me mandou para o exterior para voltar logo, poucos meses depois, e esses meses se transformaram em infinitos anos.

Memória - Você foi direto para a Itália?

José Luiz - Não, passei por vários países latino-americanos.

Memória - E Milão?

José Luiz - Sempre eu tinha ouvido falar que São Paulo e Milão eram cidades iguais, parecidas, politicamente gêmeas. Eu achava que Milão era igual a São Paulo mesmo. Evidentemente era uma Milão que poderia ter alguma coisa parecida nos anos 60. Claro, Milão é uma cidade magnífica, mas piorou muito porque foi afogada pelo automóvel. Esse é um dos grandes problemas de Milão.

Memória - E nisso não parece com São Paulo?

José Luiz - Não, absolutamente. Não há mais um metro quadrado para andar em Milão. Não tem mais calçada. Você tem que andar por cima de carros.

Memória - Hoje, no Brasil, se começa a ter uma preocupação com preservação da história, sobretudo em São Paulo e no interior. Na Itália as pessoas estão engajadas nessa questão?

José Luiz - Numa cidade como Milão, em muitas cidades europeias, você vê plaquinhas nas ruas, em tudo quanto é lado, aqui morreu o resistente tal, aqui passou Albert Einstein, aqui o imperador do Brasil Pedro II ratificou a Abolição. Veja: as placas dão uma primeira ligação com a história.

Memória - No Brasil você tem placas de rua, mas não se sabe nem quem é. José Luiz - É que na maioria absoluta das vezes não merece saber quem é. Em Milão, há, portanto, esta preocupação, até física, com a história.

Memória - Fora do Brasil algum tempo, você teria alguma sugestão de forma que a população tivesse um maior contato não só com a história do país, mas também com sua história.

José Luiz - Na Itália houve um fenômeno atípico para as massas aprenderem noções de sua história. E o responsável foi o Partido Comunista Italiano, um partido de milhões de inscritos. Ele se organizou com escolas e várias casas do povo, por exemplo. À noite, você ia jogar bocha, dominó e beber vinho (ótimo, não é?) e tinha um curso. Quer dizer, ele fez um fabuloso ensino da história à massa.

Memória - Há, no Brasil, condições de fazer isso?

José Luiz - Não, evidentemente, sobretudo pela desorganização do país. Mas acho que os sindicatos têm um grande dever, uma grande responsabilidade. Sei que o líder sindical muitas vezes não tem tempo, isto é, fica 24 horas por dia planejando como aguentar o novo golpe que vem de 
algum ministério, tem que ficar ali lutando pelo salário mínimo. Mas é uma obrigação daqueles que sabem se aproximar desses líderes sindicais e ajudálos no que for. É que o Brasil é grande, a população brasileira é grande. O número de jovens é desesperador. Só no Estado de São Paulo temos mais de 6 milhões de alunos. De qualquer forma, dá para fazer através de sindicatos. Outro setor seria a sociedade amigos de bairros. Governos democráticos deveriam dar uma contribuição maior. Acho, porém, que o simples fato de existir o Centro de Memória Sindical, o Arquivo Leuenroth, que ajudam em muitas teses universitárias, melhorou muito. O movimento negro existe e começa a estudar sua história. Mesmo o índio diz: "Espera um pouco branco, a história não é bem assim. Eu tenho a minha história também". Isto é maravilhoso, avançamos muito. O problema do Brasil está no seu imenso espaço e população de 150 milhões de habitantes. Mas são 70 milhões de jovens para você ensinar. Meu Deus do céu, eu fico pensando: é preciso fazer um método tipo chinês. Aí, você olha a sua força e vê que é muito pouca. 